\title{
Optimizing processing parameters and fiber size for kenaf fiber reinforced thermoplastic polyurethane composite
}

\begin{abstract}
In this study, composite of Themoplastic polyurethane (TPU) reinforced with short fiber (Hibiscus Cannabinus) kenaf (KF) were prepared via melt blending method using Haake Polydrive R600 internal mixer. Effect of various processing temperatures, times and speeds on tensile strength was studied, together with effect of various fiber sizes on tensile, flexural properties and impact strength. Optimum blending parameters were $190^{\circ} \mathrm{C}, 11 \mathrm{~min}$, and 40 $\mathrm{rpm}$ for temperature, time and speed, respectively. Using the optimum processing parameters TPU-KF composites with different fiber sizes were prepared. Composite sheets were prepared by hot press machine at $190{ }^{\circ} \mathrm{C}$ for $10 \mathrm{~min}$. Five samples were cut from the composite sheet. Mean value was taken for each composite according to ASTM standards. Tensile and flexural strength were best for fibers between 125-300 micron. Impact strength showed an increasing trend with increasing fiber size.
\end{abstract}

Keyword: Natural fiber composites; Thermoplastic polyurethane; Kenaf fibers 